\title{
Graphical User Interface (GUI) of Digital Index Evaluation System for Finger Clubbing Identification
}

\author{
S. M. W. Masra*1, K. L. Goh'1, M. S. Muhammad ${ }^{1}$, R. D. Djojodibroto ${ }^{2}$, R. \\ Sapawi $^{1}$, K. Kipli ${ }^{1}$, and N. S. Shahrom ${ }^{1}$ \\ ${ }^{1}$ Department of Electrical and Electronic Engineering, Faculty of Engineering, UNIMAS, \\ 94300 Kota Samarahan, Sarawak, Malaysia. \\ ${ }^{2}$ Department of Medicine, Faculty of Medicine and Health Sciences, UNIMAS, \\ 94300 Kota Samarahan, Sarawak, Malaysia. \\ E-mail:wmmasnia@unimas.my
}

Received: 7 February 2017

Accepted: 9 October 2017

\section{ABSTRACT}

This paper presents the development of a Graphical User Interface (GUI) for calculating the sum of nail-fold (NF) and distal interphalangeal joint (DIP) ratios for all ten fingers. The sum of NF:DIP ratios for all ten fingers leads to the Digital Index (DI) that was used as the measure for identifying and determining the presence of finger clubbing symptom. This GUI system was developed to serve as a simple and user-friendly interface for clinicians to calculate DI value of patients in a busy clinic practice. It is also equipped with the capability to keep the patient's past diagnosis medical check-up data for future monitoring purposes. The result shows that the developed system helps the clinicians to perform calculation of DI value and identify the presence of finger clubbing in a very short time. The average time taken to measure both NF and DIP circumferences using Finger Clubbing Meter, and to compute DI values using Digital Index Evaluation System (DIES) interface is 6:36 $\pm 1: 24$ minutes (Mean $\pm S D$ ). This system is expected to contribute in detecting the finger clubbing problem at early stage of so the treatment can be performed immediately.

Keywords: finger clubbing, digital index, nail-fold, distal interphalangeal joint, graphical user interface 